\title{
Los tortuosos caminos de la migración venezolana en Sudamérica: tránsitos precarios y cierre de fronteras
}

\author{
The winding roads of Venezuelan migration in South America: \\ precarious journeys and closed borders
}

Gioconda Herrera Mosquera*

ISSN IMPRESO 1870-7599 | ISSN RED CÓMPUTO 2448-7783 | 33-56

Gabriela Cabezas Gálvez** RECIBIDO 28/02/20 | ACEPTADO 16/03/20

Resumen. Este artículo examina la reciente migración venezolana a Colombia, Perú y Ecuador, que son actualmente los destinos con el mayor número de presencia venezolana en la región sudamericana. El texto centra su análisis en dos características centrales de esta migración: la tendencia a mantener trayectorias migratorias con múltiples destinos y la precariedad laboral. Se sostiene que ambas dimensiones de la dinámica migratoria se relacionan con la crisis económica en los países de acogida y el progresivo endurecimiento de las políticas migratorias. Los movimientos de retorno que ha emprendido la población venezolana desde distintos lugares de América del Sur durante la pandemia de la covid-19 pueden explicarse también a partir de esas dinámicas.

Palabras clave: migración venezolana, inserción laboral, políticas migratorias, flujos migratorios en América del Sur.

\begin{abstract}
This article examines recent Venezuelan migration to three South American countries: Colombia, Peru and Ecuador, which are currently the destinations showing a higher amount of Venezuelan presence in the region. The analysis centers on two key characteristics of this migratory experience, which are the tendency to pursue migratory paths that have multiple destinations and labor precarity. It finds that these two dimensions of the migratory dynamic are related to the economic crisis in neighboring countries and the continued toughening of migration policies. The return flows of migrants that have been undertaken by the Venezuelan population from various South American locales during the covid-19 pandemic may also explain these dynamics.
\end{abstract}

Keywords: Venezuelan migration, labor insertion, migratory policies, South American migratory flows.

\footnotetext{
* Ecuatoriana. Profesora titular del departamento de Sociología y Estudios de Género de la Facultad Latinoamericana de Ciencias Sociales (Flacso), sede Ecuador. Correo-e: gherrera@flacso.edu.ec

** Ecuatoriana. Coordina la especialización de Migraciones Internacionales, Desarrollo y Derechos Humanos de la Facultad Latinoamericana de Ciencias Sociales (Flacso), sede Ecuador.
} 


\section{Introducción}

Uno de los efectos no esperados de la covid-19 sobre las migraciones en el continente americano ha sido los procesos de movilidad en medio de las restricciones y el cierre de fronteras impuestos por prácticamente todos los Estados de la región. Hemos asistido al retorno de migrantes internos que salen de las grandes ciudades hacia sus comunidades, como es el caso de los pobladores de Lima en Perú o Guayaquil en Ecuador que se movilizaron hacia sus comunidades. También migrantes bolivianos atravesaron las fronteras argentinas y chilenas para regresar a sus ciudades y pueblos de origen. Por lo general, los motivos tenían que ver con la pérdida de trabajos y de medios de subsistencia, porque se quedaron sin vivienda o para protegerse del contagio de la covid-19. Sin embargo, tal vez lo más impactante ha sido ver el desandar de la población venezolana que ha emprendido el camino de regreso desde Perú, Ecuador y sobre todo Colombia. Con la interrupción de la circulación de medios de transporte, este regreso se hace en muchas ocasiones a pie y los migrantes han enfrentado la militarización de las fronteras, la peligrosidad de los pasos irregulares y la inclemencia climática. Sin duda, este fenómeno necesita ser examinado con mayor detenimiento, en relación con reacciones parecidas que han ocurrido en otros continentes, pues forma parte del repertorio de consecuencias no esperadas de la pandemia.

Dicho fenómeno constituye, en este texto, el punto de partida para el análisis de la migración venezolana de los últimos años en Sudamérica. Tales retornos no esperados son probablemente la expresión de una dinámica social y migratoria ya presente en la migración venezolana en América del Sur, y en particular en la región andina, que se agudiza con la pandemia. En primer lugar, está la idea de una migración en contextos de crisis (Gandini, Lozano y Prieto, 2019), pues el éxodo se produce, por un lado, debido a la aguda crisis social, política y económica sin precedentes de Venezuela y, por otro, en un escenario de desaceleración económica muy importante para América Latina. En efecto, los principales destinos de esa migración en la región son ciudades que conocen procesos de recesión en sus mercados laborales, ajustes en sus políticas sociales y giros relevantes en sus políticas migratorias hacia la securitización (Herrera y Cabezas, 2019; Herrera y Berg, 2019). Este contexto influye en las formas de integración socioeconómica de la población migrante y en la manera en que 
ésta es percibida por las poblaciones receptoras, con lo que se intensifican ciertos procesos de xenofobia. En consecuencia, la migración venezolana reciente enfrenta situaciones de precariedad muy agudas.

En segundo lugar, se trata de una migración con dinámicas de movilidad bastante más complejas que el trayecto lineal de un solo lugar de salida para asentarse en otro. Debido a una combinación de factores examinados durante la investigación, la migración venezolana tiende a experimentar tránsitos prolongados, movimientos permanentes entre ciudades y la creación de corredores migratorios en toda la región. Como se verá, muchas de las trayectorias migratorias muestran movimientos frecuentes de las personas y por lo general se vinculan con situaciones de precariedad e inestabilidad laboral, con políticas migratorias nacionales disuasivas que dificultan la regularización y con la ausencia de políticas locales que promuevan el asentamiento y la integración. Asimismo, la movilidad es alentada por el uso intensivo de redes sociales y de tecnologías de información, por la presencia de redes migratorias importantes que se extienden en varias ciudades y países de la región, y el impulso subjetivo por buscar nuevos horizontes de supervivencia. Pensamos que la combinación de esos factores - estructurales, institucionales y subjetivos - se exacerba y produce, entre otras cosas, la idea de retornar, inclusive caminando, como parte de las respuestas de los migrantes a la pandemia.

Por lo anterior, en este artículo reflexionamos acerca de los dos factores que caracterizan la reciente migración venezolana — precariedad y movimientoen tres países sudamericanos: Colombia, Perú y Ecuador, que son actualmente los destinos con el mayor número de presencia venezolana en la región. La evidencia proviene de dos investigaciones realizadas en 2018 y 2019. La primera estuvo orientada a analizar los obstáculos jurídicos que encuentra la migración venezolana para su llegada, asentamiento y regularización, ello nos permitió también recabar información sobre trayectorias migratorias y laborales de población venezolana (Herrera y Cabezas, 2019). La segunda estuvo enfocada en la situación de la niñez y adolescencia migrante en cuatro países sudamericanos e incluyó la reconstrucción de las trayectorias migratorias de sus familias (Herrera, 2020). En una primera sección presentamos las características de estos flujos en los tres países y su acento en trayectorias migratorias con múltiples destinos. Una segunda sección examina el carácter progresivamente disuasivo de las políticas migratorias de los tres Estados frente a la migración venezolana; y en una tercera parte explicamos los procesos de inserción laboral y la precariedad 
de dicha migración. Concluimos con algunas reflexiones de cómo estas dos dimensiones de la dinámica migratoria venezolana se exacerbaron en la pandemia y produjeron, entre otros efectos, el que algunos migrantes busquen regresar a casa.

\section{El éxodo venezolano: crecimiento vertiginoso y trayectorias diversas}

A lo largo del siglo XX Venezuela fue un país eminentemente receptor de migrantes. Desde los 1950, en la posguerra, Venezuela se convirtió en un lugar de acogida para migraciones mediterráneas, portuguesas, italianas, españolas y de Medio Oriente que se asentaron en ciudades como Caracas y Maracaibo por su dinámica actividad comercial. Entre los 1960 y 1980 el boom de la actividad petrolera atrajo migraciones de toda América Latina y en especial de la región andina y del Caribe. Trabajadores peruanos, ecuatorianos y dominicanos se asentaron con sus familias en una Venezuela en plena expansión económica. En la década de 1970 llegaron argentinos, chilenos y uruguayos exiliados de las dictaduras del Cono Sur (Delgado y Abellana, 2009; Cañizales, 2018). Ya en los 1980 Caracas era una de las ciudades con mayor presencia de ciudadanos latinoamericanos de diversa procedencia y mantenía una herencia inmigratoria mediterránea muy acentuada. Para 1977, de acuerdo con Raquel Álvarez de Flores (2007), 10 por ciento de la población en Venezuela era extranjera. Pero es desde Colombia que ha existido un flujo constante a lo largo de todo el siglo XX y entrado el siglo XXI. Según datos del Instituto Nacional de Estadística de Venezuela, en el censo de 2011 había 721 mil 791 residentes colombianos que representaban 70 por ciento de toda la población extranjera.

Esta tradición de país receptor hizo que Venezuela, desde finales de la década de 1980 cuando sobrevino la primera crisis económica, cerrara progresivamente sus fronteras a la inmigración y exigiera visados a los ciudadanos de los países andinos hasta bien avanzada la década de los 2000. Asimismo, su posición en la política migratoria sudamericana fue bastante cauta frente a la apertura y libre circulación de personas, con excepción de los países fronterizos. No obstante, en esas épocas de crisis económicas puntuales de los 1980 y 1990, la población venezolana tenía todavía oportunidades y no había una emigración masiva como ocurrió en los últimos años. Sólo se produjeron algunos flujos 
pequeños de retornos de descendientes de inmigrantes europeos y migración calificada (Freitez, 2019).

El aumento de salida de la población venezolana empezó con el cambio de siglo. Bajo el gobierno del presidente Hugo Chávez, sectores de clase media y alta emigraron a Estados Unidos, que triplicó la emisión de visas de residencia para población venezolana entre 2000 y 2010 (Delgado y Abellana, 2009). Además, a partir de 2010 creció la salida de venezolanos a España, muchos de ellos se beneficiaron de la posibilidad de obtener residencia y ciudadanía europea al ser descendientes de migrantes italianos y españoles.

Desde 2015 los venezolanos empezaron a migrar a Sudamérica y en 2018 tuvo lugar un verdadero éxodo, con un crecimiento vertiginoso de la emigración a consecuencia del deterioro de las condiciones de vida y un contexto que constituye una amenaza a la subsistencia y a la salud, en otras palabras, la existencia de una verdadera crisis humanitaria en ese país. Actualmente, se calcula que han salido de Venezuela un poco más de 5 millones de personas y que alrededor de 3 millones se encontrarían en Sudamérica. Las cifras reales podrían ser más altas si se tienen en cuenta los flujos de población no registrada en los diferentes países y la falta de datos consolidados y oficiales. La Plataforma de Coordinación para Refugiados y Migrantes de Venezuela (R4V) calcula un subregistro de 30-40 por ciento en las cifras (R4V, 2019). Colombia se ha convertido en el principal país de destino de la población venezolana en la región con alrededor de un millón 500 mil personas (Torrado, 2019); le sigue Perú con 860 mil; en Chile se habla de una población de aproximadamente 371 mil; en Ecuador se manejan cifras de alrededor de 330 mil 414; en Argentina alrededor de 180 mil; y en Brasil las cifras sobrepasan las 253 mil personas (R4V, 2019).

El éxodo venezolano ha llegado a ser comparado con otras migraciones provocadas por situaciones de violencia, es el caso de la población en Siria, Afganistán, Somalia, entre otros, que han tenido también incrementos acelerados y de mucha precariedad (OEA, 2019). Sin embargo, la condición de la población difiere de aquella expulsada por conflictos armados o por guerras. Los motivos esgrimidos por los habitantes para dejar su país y los indicadores sociales y de inseguridad sí muestran una crisis humanitaria sin precedentes que aparece como la principal causa de una migración masiva. Como se detallará más adelante, los Estados latinoamericanos han tratado principalmente a esta migración como una migración económica y hay muy pocos casos de reconocimiento de la condición de refugiado, según la amplia definición de la 
Declaración de Cartagena. A continuación se mencionan algunas razones de sus salidas:

Cuando estábamos en Venezuela, lo que teníamos que hacer era tratar de dormir todo el día para tener una sola comida, o sea, teníamos un poquito de merienda y la cena, pero no teníamos qué comer (Gabriela, 17 años, Bogotá).

Yo me vine porque pasaba mucha necesidad, estaba embarazada. No estoy feliz porque salí de mi país, pero salgo por el futuro de mi hijo. Si no tuviera a mi hijo estaría allá con mi familia. Pasando hambre, pero allá, estudiando en el liceo y tendría mi foto [de graduación] (Rosa, 18 años, Guayaquil).

Mi familia siempre busca una estabilidad y era de por sí muy difícil el transporte, conseguir efectivo, conseguir la comida, era escasa y se conseguía en pocos lugares. Estas dificultades son las que obligaron a mi familia a pensar en un mejor futuro. (...) Difícilmente, se podía comer todos los días (Alexandra, 16 años, Lima) (Herrera, 2020:119).1

La escasez de alimentos y medicinas, además de dificultades en los suministros de servicios básicos como la electricidad, el agua, el gas y las bajas remuneraciones en los empleos, son algunas de las manifestaciones de esta crisis, que son mencionadas por los entrevistados como factores que catalizan dicha migración sin precedentes en la región.

En 2018, según datos de la Encuesta de Condiciones de Vida (Encovi) de Venezuela, cerca de 91 por ciento de la población vivía bajo condiciones de pobreza por ingreso; 8 de cada 10 hogares se encontraban en condiciones de inseguridad alimentaria; la mortalidad infantil aumentó y se perdió la esperanza de vida en un promedio de 3.5 años. Para el 2019, la encuesta ratifica que 87 por ciento de los hogares en el país está en la categoría de pobres y 80 por ciento en inseguridad alimentaria. También se muestra que 89 por ciento de las familias no logra los ingresos suficientes para comprar alimentos. A esa situación de pobreza se suman los problemas en la atención médica, las altas tasas de violencia social e inseguridad, con aumento del crimen organizado, los problemas de infraestructura y de servicios que provocan recurrentes cortes de luz y agua y afectan en el vivir cotidiano. Complementariamente, las encuestas captaron

${ }^{1}$ Esta información proviene del capítulo "Colombia», realizado por Tania Correa del informe de investigación «Voces y experiencias de la niñez migrante venezolana en Brasil, Colombia, Ecuador y Perú», bajo la coordinación de Gioconda Herrera, el cual fue publicado posteriormente por Clacso. 
que 90 por ciento de las personas que decidieron migrar lo hizo entre 2015 y 2017, y casi un millón 500 mil hogares declararon tener al menos un miembro del hogar fuera del país (Freitez, 2018; Freitez, 2019). Se trata, entonces, de una migración desencadenada por contextos amplios de adversidad causados por el fuerte deterioro del nivel de vida y de los servicios sociales en Venezuela.

\section{Crecimiento vertiginoso de los flujos}

Concerniente a la evolución de los flujos en los tres países es evidente el crecimiento exponencial de personas venezolanas en los últimos tres años. En Perú, las cifras oficiales de la Superintendencia Nacional de Migraciones, a julio del 2019, contabilizan a 850 mil venezolanos que ingresaron al país, lo anterior sin considerar que el Perú, en menor medida, es un destino de paso hacia Chile (OIM, 2018a; OIM, 2018b; Estado Peruano, 2019). A junio de 2020, de acuerdo a la R4V, habría 628 mil 976 personas regularizadas en ese país. El perfil de las personas venezolanas en Perú ha ido cambiando en los dos últimos años, en un inicio eran en su mayoría hombres jóvenes; no obstante, para el 2018, la «Encuesta dirigida a la población venezolana que reside en el país» (Enpove) muestra que 52.3 por ciento son efectivamente hombres, frente a 47.7 por ciento de mujeres, casi la mitad de la población venezolana en ese país. Sobre la estructura de edades hay una predominancia de la población económicamente activa: 71.8 por ciento se encuentra en el rango de edad de 18 a 59 años, si bien destacan los jóvenes de 18 a 29 años con 42 por ciento, seguido de las personas de 30 a 44 años con 29.8 por ciento; mientras que 18.7 por ciento son menores de edad, 10.8 por ciento son niños y adolescentes en edad escolar (INEI, 2018).

En cuanto al Ecuador, la población venezolana instalada es relativamente joven también, lo que coincide con los datos que presenta la población en Perú. Del total de la población captada en los registros migratorios del Ministerio del Interior, hasta junio de 2020, había un saldo migratorio acumulado de aproximadamente 363 mil 23 personas venezolanas, de las cuales 179 mil 787 estarían regularizadas (R4V, 2020). Un dato interesante es que en 2020, por primera vez en 10 años, el saldo migratorio es negativo, es decir hay más personas venezolanas (3 mil 709) que han salido de Ecuador (R4V, 2020), con lo que se demuestra una tendencia a la remigración o inclusive al retorno. La distribución porcentual entre hombres (52 por ciento) y mujeres (48 por ciento) es equilibrada, como sucede en Perú y Colombia. Las edades que más se engrosan en la distribución 
de las pirámides comprenden entre los 20 y los 45 años. En el 2019, 76 por ciento de los ciudadanos venezolanos captados en el acervo de los saldos migratorios tenía entre 18 y 55 años, alrededor de 21 por ciento de la población era menor de edad y casi 11 por ciento tenía menos de 10 años. Respecto a la distribución del estado civil, podemos hablar de dos perfiles: por un lado, de personas solteras o divorciadas, sin hijos; y, por otro, parejas jóvenes con hijos menores de edad (Ministerio del Interior, 2018; Herrera y Cabezas, 2019).

Referente a Colombia, el destino principal de este flujo migratorio tiene una relación histórica con Venezuela. Cabe resaltar que durante muchos años Venezuela recibió a numerosos migrantes colombianos. En la década de 1970, profesionales atraídos por el boom petrolero llevaron a sus familias por trabajo y se instalaron en el país, de manera que se tiene población de primera y hasta segunda generación, que posiblemente cuenta con la doble nacionalidad. En adición, para la década de 1990, llegaron personas desplazadas por la violencia del conflicto armado en Colombia. Según los datos presentados por el Registro Administrativo Migratorio, corte al 31 de marzo de 2019, en Colombia residiría un acumulado de alrededor de un millón 260 mil 594 personas venezolanas y sólo 770 mil 975 tendrían una situación regular desde que comenzó la crisis en Venezuela. Según el Registro Administrativo de Migrantes Venezolanos (RAMV) alrededor de un millón 800 mil venezolanos se han instalado en ese país (R4V, 2019). La distribución por sexo es igualmente equitativa: 50.2 por ciento hombres y 49.8 por ciento mujeres. Con una distribución porcentual en las edades de 74 por ciento de 18 años y más, con una concentración en las edades productivas y reproductivas similar a la de Perú y Ecuador, y 26 por ciento de menores de 18 años de edad, lo que confirma el alto porcentaje de niños y adolescentes (Migración Colombia, 2019; Castro, 2019). El RAMV 2019 indicó que 47 por ciento de la población venezolana que ingresa a Colombia proviene de los departamentos fronterizos y 53 por ciento del resto del país (R4V, 2019).

Respecto a las características de estos flujos en los tres países, es importante subrayar el carácter diverso de los migrantes: provienen de varias ciudades de Venezuela, pertenecen a distintos estratos socioeconómicos que se expresan en el nivel educativo y de acuerdo a los trabajos que dejaron en Venezuela; algunos son viajeros solos, otros se desplazan con sus familias. Esta diversidad es producto de distintas etapas migratorias. En el caso de Perú y Ecuador, a partir de 2016 empiezan a llegar sectores de clase media cada vez más empobrecida, con niveles educativos universitarios y con empleos públicos o en el sector privado en áreas 
administrativas (Herrera, 2019). De modo progresivo el flujo va cambiando y a finales de 2018 y en el 2019 son sectores más empobrecidos aún los que predominan en las nuevas llegadas, que conforman un grupo muy amplio de trabajadores y familias en condiciones muy precarias, quienes, como se verá después, encuentran muchas dificultades para insertarse en mercados laborales. En esta segunda etapa existen poblaciones vulnerables que en otros momentos no migrarían: mujeres embarazadas, personas con discapacidades o de la tercera edad, niños y adolescentes. Ello lo corroboran distintos estudios en Colombia, Perú y Ecuador (Cabrera, Cano y Castro, 2019; Herrera y Cabezas, 2019; Blouin y Freier, 2019). En 2020, la tendencia parece indicar un estancamiento de los flujos e inclusive una disminución de los saldos migratorios, como en Ecuador, lo cual es consecuencia de la imposición de la visa para entrar al país y de una dinámica de remigración.

Es pertinente aclarar que existen diferencias en las formas de asentamiento en los tres países que tienen efectos en las dinámicas migratorias de la población migrante y en el impacto sobre la población local. Mientras que en Perú la migración venezolana se concentra en 90 por ciento en la ciudad de Lima, en Ecuador se encuentra distribuida prácticamente en todo el territorio (BM, 2020) y en Colombia hay una alta concentración en Bogotá, Barranquilla, Medellín y en ciudades fronterizas como Cúcuta o Guajira.

Referente a las características educativas de la población, en un inicio del éxodo venezolano se registró una población con niveles educativos altos en los tres países. En Perú, en 2018, el Instituto Nacional de Estadística e Informática (INEI) reveló que 37.9 por ciento de la población venezolana tenía estudios universitarios (24.9 por ciento estudios completos); 19.2 por ciento estudios técnico superiores (15.5 por ciento estudios superiores completos); y 31.9 por ciento logró estudiar la educación secundaria, del cual 25.9 por ciento completó sus estudios (INEI, 2018).

En Ecuador, la encuesta del Banco Mundial (BM) aplicada en julio de 2019 en todo el país reveló que la mayoría de la población venezolana cuenta con educación secundaria y la proporción de población con educación de tercer nivel es superior para los migrantes, en particular para las mujeres (BM, 2020:22). De acuerdo con algunos estudios cualitativos recientes (Moreno, 2018; Herrera y Cabezas, 2019), así como los datos de la Secretaría Nacional de Educación Superior, Ciencia y Tecnología (Senescyt), la población venezolana que llegó entre 2016 y 2018 presentaba niveles de educación más altos. La Senescyt ha reconocido 
un total acumulado de 25 mil 708 títulos profesionales de venezolanos entre 2013 y 2018, lo que corresponde a 10 por ciento del total de venezolanos en el país. Cabe destacar que 80 por ciento de las revalidaciones universitarias se concentraron en los últimos tres años y 55.13 por ciento corresponde a mujeres. El registro de títulos universitarios en Ecuador es uno de los requisitos para la obtención de una visa profesional y acceder a un trabajo en el sector público, en especial para médicos y enfermeras (Herrera y Cabezas, 2019). La información de los altos niveles escolares en la población venezolana residente y de tránsito en Ecuador ha sido corroborada por otros estudios cuantitativos que muestran que entre 25 y 30 por ciento de venezolanos cuenta con niveles universitarios que no necesariamente ha sido ingresada en el trámite de la Senescyt porque carecen de los títulos apostillados (Celleri, 2019).

Por su parte, en Colombia se confirma que cerca de 60 por ciento de la población regularizada tenía un nivel de escolaridad universitario o técnico superior en el 2018. Sin embargo, al parecer el perfil educativo de la población recién llegada ha cambiado, ya que ha aumentado el nivel de educación secundaria. En contraste, en los poblados y ciudades fronterizos la población migrante venezolana tiene menores niveles educativos y está generalmente más empobrecida (Herrera, 2019). Según cifras del Displacement Tracking Matrix (DTM), en diciembre de 2018, 30 por ciento de la población venezolana encuestada en las localidades de frontera tenía estudios universitarios o técnico superiores y más de 60 por ciento alcanzaba los niveles de estudios secundarios o de bachillerato (OIM-DTM, 2018).

En definitiva, en la actualidad los tres países estudiados experimentan una migración venezolana cuyo crecimiento y diversificación ha sido muy veloz, con una relevante presencia de menores de edad y de familias nucleares y ampliadas, sin grandes diferencias entre hombres y mujeres y con perfiles educativos relativamente altos, pero que están cambiando con rapidez hacia personas con niveles de escolaridad secundaria.

\section{Dinámica migratoria}

Relativo a la forma en que se organiza esta migración, algunos trabajos recientes han observado que asistimos al viaje escalonado de familias, muchas de ellas se localizan en varios destinos del continente, algunas permanecen separadas por varios meses y años y existe una movilidad muy frecuente de una ciudad a otra, 
tanto al interior de los tres países como entre países (Herrera y Cabezas, 2019; Cabrera, Cano y Castro, 2019; Blouin y Freier, 2019). También se ha indicado la presencia de niños y adolescentes que viajan sin sus padres o madres, ya sea con alguna persona de la familia o solos, que se están trasladando con el fin de reunirse con sus padres (Selee, Bolter, Muñoz-Pogossian y Hazán, 2019; Herrera, 2019).

Uno de los rasgos más sorprendentes de esta migración en los dos últimos años es su forma de desplazarse. Al inicio del éxodo se combinaban los distintos medios de transporte aéreo, terrestre y a pie. Desde finales de 2018 la población venezolana llega sobre todo y únicamente caminando, en viajes que pueden tomar varios meses, por rutas diferentes y con trayectorias de movilidad muy diversas:

Yo no me vine por San Antonio del Táchira. Yo me vine por Maicao. Maicao es un sector comercial. (...) Te sellan y paso a la ciudad más cercana que se llama Valledupar, que es una tierra de vallenato, por supuesto. Es una ciudad parecida a un pueblo, sin mucho comercio. No es industrializada. Me quedé dos meses, no quise estar más, no me gustaba. A lo largo de esos dos meses en Colombia caminaba del trabajo a mi casa, creo que una hora y media a pie, para no pagar transporte porque era costosísimo. (...) De Valledupar yo me vine a Ecuador. Sí, de Valledupar hasta Cali me costó 27 dólares, 100 pesos, y hasta Cali a la frontera, 15-12 dólares, y 11 dólares más llegué a Quito; calculé hasta el último centavo (Juan, 30 años, Quito).

A los viajes prolongados se suman también experiencias de remigración en varios países. Es el caso de Jerson, un joven vendedor ambulante de la ciudad de Guayaquil, proveniente de la Costa Caribe, quien salió de ahí hace tres años con destino a Panamá, donde residía su padre; trabajó seis meses allí en la construcción y luego se dirigió a Colombia, donde vivían unos primos con quienes estuvo un año. Luego viajó a la ciudad de Santo Domingo, en Ecuador, donde se hallaban su madre y sus hermanos menores, pero al no conseguir trabajo se trasladó a Guayaquil, sitio en el que sus posibilidades de ganar dinero con la venta ambulante son mayores. Jerson empezó su migración siendo menor de edad, lo cual no le impidió movilizarse, siempre organizó sus movimientos en grupos y sin pasar por las fronteras formales. En Colombia pasó por trochas hasta las ciudades fronterizas, es una experiencia que forma parte de la memoria de esta migración.

Generalmente, las trayectorias migratorias coinciden en señalar que en una primera etapa, luego del paso de la frontera, se instalan en una de las ciudades 
fronterizas por varios días y hasta varios meses. La siguiente fase es continuar hacia otra ciudad en Colombia o hacia otro país: «El viaje de Barranquilla a aquí (Bogotá) me dio más miedo que el de Venezuela, luego de varias semanas decidimos venir por las montañas. Las curvas, yo veía las carreteras y tenía miedo de que se volteara el bus» (Juan Carlos, 16 años, Bogotá). Descubrimos historias parecidas en la frontera de Colombia con Ecuador, de migrantes con tránsitos prolongados y con destino a Perú o Chile, pero que trabajaban de modo temporal en la ciudad de Tulcán.

Para las personas migrantes cuyo destino final era una ciudad en Perú, las trayectorias migratorias podían durar días, semanas y meses, con periodos de estancias en diferentes ciudades, mientras trabajaban de forma precaria con el objeto de reunir el dinero necesario y continuar el viaje. Es la historia de María y Ramiro, quienes permanecieron en Quito por casi dos años, tuvieron una hija en esa ciudad y luego siguieron su trayecto hasta Lima, ahí se reunieron con las hermanas de María. En Quito la pareja trabajó en varios empleos precarios de ventas ambulantes, estéticas, lavadoras de autos, entre otros.

Él (su esposo) me llevó desde mi pueblo hasta la frontera en el carro. Lo dejé en la frontera por Orope, nos despedimos y de ahí siguió. Orope es la frontera del Táchira a Colombia. Dejamos el carro en un sitio y pasamos la frontera. No es Cúcuta, es otra entrada. Pues la otra frontera era por San Antonio en el estado de Táchira, entonces esa sí es complicada. Por eso hicimos esa ruta más corta, porque yo venía con el niño, maleta y todo. (...) En Orope, ahí compré el ticket hasta Cúcuta. CúcutaBogotá, Bogotá-Ipiales. De ahí, Ipiales-Tulcán, sellé en Rumichaca. Me fui a Tulcán y de ahí a Quito. (...) Nos vamos el próximo sábado a Lima donde está mi familia, ya no tenemos trabajo y mi bebé ya está grande (María, 37 años, Quito).

Es decir, existe una dinámica de movilidad muy intensa entre la población venezolana, relacionada con el viaje y con asentamientos temporales en varias ciudades: «Llegué el 17 de abril aquí (Quito), me toca salir el 17 de octubre. He pasado casi cuatro meses. [...] Me voy a Perú, octubre, noviembre, diciembre y de ahí me voy a Venezuela en avión porque es más económico el vuelo por allá» (Simón, 41 años, Quito).

En efecto, la migración venezolana ha impactado en los tres países andinos por la intensidad, la cantidad y la velocidad de su llegada. Los viajes pueden durar varios días, semanas y meses, porque los trayectos no son lineales, ni 
directos. Más bien tienden a ser escalonados, por etapas, se llega a las primeras ciudades hasta donde alcance el dinero, se instalan por un tiempo y vuelven a migrar hacia un nuevo destino, que no necesariamente es un destino final. Al contrario, la falta de empleo y la presencia de redes migratorias en varias ciudades y países propician el movimiento e incluso el retorno a Venezuela.

\section{Políticas migratorias progresivamente disuasivas y cierre de fronteras}

¿De qué manera las políticas migratorias impulsan o inhiben estos procesos de movilidad constante? ¿Hasta qué punto se ha favorecido el asentamiento? Los tres países en cuestión han pensado sus políticas desde una visión de países emisores de migrantes y no cuentan con una experiencia histórica de inmigración. Tampoco tienen políticas públicas adecuadas como países receptores (Freier, 2019). Por ello, la sorpresiva llegada de la población venezolana ha significado repensar las políticas de inmigración sobre la marcha o activar mecanismos discrecionales. Esto ha implicado cierta inestabilidad y cambio en las reglas de juego, situación que ha perjudicado la regularización de migrantes y su positiva inclusión social en los lugares de destino.

En general, los tres países empezaron tomando medidas que denotaban cierta apertura hacia la inmigración venezolana, pues privilegiaron enfoques específicos de derechos humanos por encima de perspectivas securitistas y de control de los migrantes. Sin embargo, éstas se fueron endureciendo con la llegada cada vez más creciente de inmigrantes. De acuerdo con Luisa Feline Freier y Soledad Castillo Jara (2020), entre 2015 y 2019 Perú y Ecuador pasaron de una posición que facilitaba la entrada y la regularización de la población, a un cierre de la frontera a mediados de 2019, al frenar drásticamente la circulación de la población migrante por pasos regulares y al provocar el crecimiento de pasos irregulares y el tráfico de personas. En Perú, el gobierno implementó el Permiso Temporal de Permanencia (PTP) en enero de 2017 y desde esa fecha hasta junio de 2019 se establecieron diversas directivas orientadas a otorgar un estatus temporal especial a los ciudadanos venezolanos que les permitía trabajar. Después de esa fecha, las personas venezolanas sólo pueden ingresar al Perú mediante una visa humanitaria tramitada en Venezuela, Colombia y Ecuador, con lo cual se imponen mayores barreras de ingreso y control. En la práctica 
esta visa es muy difícil de obtener para la gran mayoría de solicitantes, pues se requiere de un pasaporte y en la actualidad sólo una minoría puede acceder a ese tipo de documento. En estos momentos en Venezuela son muy complicados los trámites de documentación, el sistema administrativo ha colapsado y se han producido y consolidado redes de corrupción que tramitan pasaportes, apostillan documentos y otros (Gandini, Lozano y Prieto, 2019; Freitez, 2019).

Hasta 2019 la población venezolana podía entrar libremente a Ecuador con pasaporte, cédula de identidad venezolana y carta andina, esta última era otorgada en una de las jefaturas migratorias en caso de no tener ningún otro documento. En varios artículos de la Constitución se manifiesta el derecho a la libre circulación y a migrar sin restricción de fronteras. ${ }^{2}$ Para regularizar su situación, los migrantes podían recurrir a tres formas: la primera posibilidad fue un tratado bilateral de 2010 que otorgaba residencia y visas de trabajo por dos años a personas que demostraran laborar de manera formal en el país. La segunda, y la más utilizada entre 2018 y 2019, fue la visa Unasur, que garantizaba un permiso laboral de dos años sin necesidad de demostrar un contrato de trabajo. La tercera concierne a la visa profesional, la cual benefició a aproximadamente 90 mil personas. Pero, a partir de septiembre de 2019, y bajo la prerrogativa de una migración segura, ordenada y regular, promulgada por el Pacto para la Migración, se solicita una visa para entrar a Ecuador, por lo que se pone en vigor la llamada visa de excepción por razones humanitarias (Verhu), o llamada de forma coloquial visa humanitaria. Si bien es menos costosa que las anteriores sólo puede ser obtenida en Venezuela o en un consulado de un país fronterizo, circunstancia que limita drásticamente la entrada y regularización de la población venezolana. Paralelamente, en septiembre de 2019 se inició un proceso de regularización de la población venezolana en el territorio, pero se restringió a las personas con pasaporte y se dejó fuera de la regularización a aquellas que entraron con otros documentos aceptados por la carta magna. Tales cambios muestran las contradicciones y tensiones entre la base constitucional de la perspectiva de los derechos humanos y la aplicación de las políticas restrictivas de control (Acosta y Freier, 2015).

Ahora, las políticas de Perú y Ecuador pasaron de la apertura a la disuasión y control (Herrera y Cabezas, 2019). Este giro se produjo por el rápido incremento de migrantes, el crecimiento de la xenofobia y el mayor peso de la política

${ }^{2}$ La Constitución del Ecuador de 2008 se basa en el enfoque de derechos humanos. En varios artículos de la carta magna se declara la protección de derechos humanos en todas las personas migrantes sin discriminación ni distinción de nacionalidad. 
interna, cada vez más adversa a la migración, por sobre la política exterior (Freier y Castillo, 2020). En contraste, en el caso de Colombia, en marzo de 2019, se impusieron nuevas medidas de control fronterizo y se solicitó a Venezuela tramitar la documentación a fin de favorecer la situación migratoria de la población venezolana en su territorio, además se facilitó que más personas venezolanas pudieran obtener con rapidez el permiso especial de permanencia (PEP) con la intención de insertarse en el mercado laboral y evitar abusos y explotación. Sin embargo, Colombia se alineó al control y gestión de las fronteras con una agenda binacional con Ecuador que plantea la necesidad de fortalecer el control de la frontera ecuatoriana-colombiana, así como la lucha contra la trata de personas y el tráfico de migrantes en el marco de los mecanismos bilaterales de seguridad y defensa existentes. Esta tendencia se radicalizó con la llegada de la pandemia y en el mes de abril de 2020 Perú y Colombia militarizaron sus fronteras. Ello trajo consecuencias muy graves para las poblaciones transfronterizas y en particular para los caminantes venezolanos que habían emprendido el regreso hacia su nación. En definitiva, las políticas migratorias se tornaron más bien disuasivas en dos de los tres países examinados y junto con la escasez de empleo y la crisis de la covid-19, las restricciones a la movilidad y el cierre de fronteras han complicado los movimientos de un territorio a otro, o de una ciudad a otra, sin que tampoco existan políticas de protección social o de integración para los migrantes.

\section{Inserción laboral: precariedad y sobrevivencia}

Algunos estudios han empezado a calificar la migración venezolana como una migración de supervivencia y no sólo económica (Freier, 2019) al referirse a que la salida de la población no sólo busca mejores ingresos, sino que huye de condiciones de inseguridad. No obstante, los primeros resultados de estudios acerca de la inserción social y laboral muestran que esas condiciones de precariedad e inseguridad tienden a reproducirse en los lugares de destino debido a la crisis económica y a la creciente xenofobia. Además, esta doble situación se exacerba durante la crisis de la covid-19. En 2016 y 2017, los primeros grupos migrantes que llegaron a Ecuador y Perú consiguieron empleos que les permitieron correr con los altos gastos de obtención de una visa de trabajo, que en el caso ecuatoriano llegaba a los 450 dólares (visa del acuerdo bilateral Ecuador-Venezuela), y 
además llevarse a su familia (Herrera, 2019). Dichas condiciones cambiaron drásticamente en 2018 y los deterioros del mercado laboral implicaron la progresiva callejización de los migrantes.

Una muestra de ello es el caso de Javier, de 37 años (gráfica 1), quien había realizado estudios de Derecho, pero no se tituló y era cajero en un banco en Venezuela. Llegó a Quito en noviembre de 2016, en el mes de diciembre ya tenía un trabajo en un restaurante de comida rápida en el que únicamente permaneció dos meses. Luego arribó su hermano y con él comenzó a vender comida en la calle. En abril de 2017 fueron contratados de forma oral en una lavadora de autos; en agosto su hermano se marchó a Venezuela y él volvió a vender comida en las calles; en octubre llegó su familia y Javier empezó a trabajar en un restaurante durante las noches. En enero de 2018 dejó el restaurante y siguió con las ventas ambulantes. Finalmente, al momento de la entrevista, en octubre de 2018, llevaba trabajando como chofer de Uber desde abril.

\section{GRÁFICA 1}

Trayectorias laborales

Javier, 37 años de edad, casado, 3 hijos, su suegra vive en la casa.

Estudió derecho en Venezuela, trabajaba en un banco.

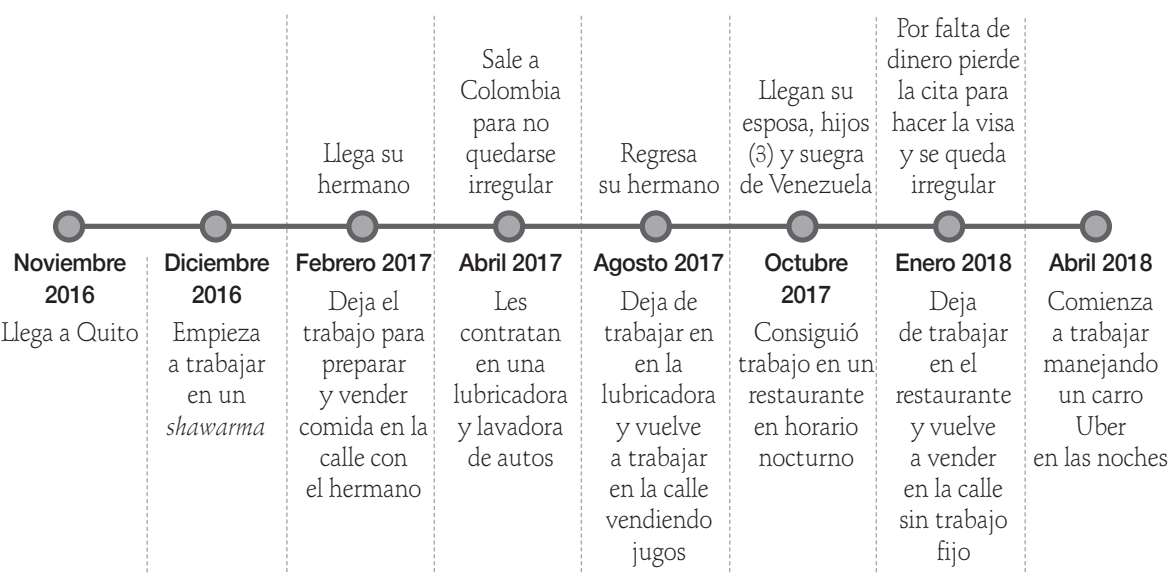

Pasan de la informalidad en la calle a la «informalidad» dentro de la formalidad de la dependencia pero sin seguridad social, sin pago justo, con maltratos y abusos de horas e inclusive abusos sexuales en el caso de las mujeres.

Fuente: elaboración propia con base en varias entrevistas realizadas (Herrera y Cabezas, 2009).

Marina, de 37 años, tenía estudios universitarios de Ingeniería en Agronomía, era soltera. Arribó a Quito en enero de 2017 y logró regularizarse con una 
visa profesional porque había preparado su salida y apostillado todos los documentos. Los dos primeros meses vivió con los pocos ahorros que había llevado consigo. En marzo de 2017 consiguió un trabajo de bodeguera por dos meses, luego se cambió a un call center donde ganaba por comisiones. Dejó ese empleo después de tres meses y empezó a hacer la limpieza en una casa y de manera alterna era empleada de un restaurante.

Estas dos trayectorias ejemplifican procesos de inserción laboral precarios, inestables y que no han mejorado en el transcurso de los años, sino que han empeorado en el caso de Marina y se han estancado en el caso de Javier. Más aún, en ambos existe una brecha importante entre los niveles de formación y el tipo de trabajo realizado. Esto lo corroboran los dos estudios y estadísticas sobre empleo de migrantes venezolanos en Ecuador y Perú, llevados a cabo por el BM $(2019,2020)$ en los que se confirma la precariedad de la inserción laboral.

De modo general, en principio y según la normativa de los tres países, las personas que se regularizan tendrían mayor facilidad de acceder a un trabajo formal con beneficios laborales. Sin embargo, dada la situación económica en los países receptores no parece cumplirse esta regla ni para los regularizados y menos para aquellas personas sin documentos de trabajo. Además, la población venezolana llega de un contexto en crisis y no puede esperar para tener una visa o un permiso de trabajo, al contrario, la necesidad de sobrevivir y de enviar dinero a sus familiares los empuja a insertarse rápidamente en los mercados de trabajo locales en empleos no calificados, con baja remuneración, expuestos a violación de los derechos laborales, con un horario extenuante y en algunos casos sin pago.

En Colombia, la población migrante venezolana económicamente activa es por lo general joven, y con mayor escolaridad que la población de acogida (Bahar, Dooley y Huang, 2018). No obstante, esta investigación evidenció que la tendencia es emplearse en la informalidad para el sustento diario. A pesar del tipo de trabajo que tenían deseaban contar con una mejor calidad de vida que en su contexto de origen (Marulanda, Cubillos, Ulloa y Prada, 2018). Las personas venezolanas se insertan en trabajos informales o en una infinidad de trabajos en servicios en distintos lugares como bares, restaurantes, tiendas, entre otros. Al parecer, al igual que en Perú y Ecuador, los empleadores abusan de la necesidad de trabajar y en contra de los derechos laborales imponen hasta 12 horas de trabajo o más, con bajos salarios y por debajo de lo establecido por la normativa laboral en Colombia. 
Según los datos de la Enpove, en Perú 91.5 por ciento de la PEA venezolana se encuentra ocupada o buscando un empleo. La PEA de esta población se caracteriza por tener cierta predominancia masculina y ubicarse en un rango de edad de 15 a 49 años. Entre la población ocupada, 78.3 por ciento son trabajadores dependientes asalariados, 48.2 por ciento son empleados (más de la mitad son mujeres), 26.7 por ciento son obreros, 3.4 por ciento son trabajadores del hogar. El otro 20.5 por ciento son trabajadores independientes. Del grupo de trabajadores dependientes, sólo 11.5 por ciento tiene un contrato laboral. Según ramas de actividad, 56.7 por ciento se desempeña en el sector servicios, sobre todo en el ámbito de restaurantes y hoteles; seguido de 21.5 por ciento en el rubro comercio; y 15 por ciento en manufactura. Respecto a los años de estudio y la inserción laboral, se puede advertir que un porcentaje importante cuenta con estudios universitarios o técnico superiores. Pese a ello, la mayoría de la población venezolana en Perú se ubica en trabajos informales (sin contrato ni beneficios laborales), en empresas pequeñas (de 1 a 10 trabajadores), en concreto en el sector servicios. Es importante mencionar que en ese contexto de inserción y situación laboral de los venezolanos alrededor de 50 por ciento de los encuestados en la Enpove manifestó ser discriminado en sus centros de trabajo por su nacionalidad.

La inserción laboral en Ecuador de la población venezolana llegada en los últimos años se produce en un contexto de desaceleración de la economía ecuatoriana con cifras de subempleo y desempleo crecientes. De acuerdo con el BM, "las tasas de desempleo, subempleo e informalidad aumentaron a niveles que no se habían visto en 10 años. Entre 2013 y 2018, se perdieron aproximadamente 66 mil empleos adecuados» (2020:26). De ahí que la inserción laboral en Ecuador esté condicionada por un mercado de trabajo muy deteriorado, el cual no logra cubrir la demanda laboral que tiene de la misma población de acogida. Casi 60 por ciento trabaja en el sector informal, en un trabajo temporal (71 por ciento) y sólo 84 por ciento ha recibido por su trabajo el pago acordado (BM, 2020. Además, los migrantes venezolanos dedican al trabajo más horas a la semana que los ecuatorianos, pero reciben un pago promedio mensual menor.

La población venezolana consigue insertarse en el mercado de trabajo informal y de manera «informal» en el mercado formal, es decir en trabajos que deberían cumplir con ciertos estándares laborales que no se llevan a cabo. Lo anterior implica que muchos empleadores de establecimientos (bares, restaurantes, tiendas y otros servicios) contraten a personas venezolanas y les paguen menos de lo que estipula la ley. Es evidente que existe una movilidad ocupacional recurrente con 
periodos cortos de tiempo de trabajo y cambios constantes de actividades, lo que da como resultado inestabilidad laboral y económica. Esto vuelve proclive una mayor movilidad entre ciudades e inclusive entre países. Varios de los entrevistados en nuestra primera investigación en 2018 ya no se encontraban en el país en 2019.

Así, las trayectorias laborales son sumamente cortas, sin las prestaciones que las leyes laborales exigen. En adición, se comprobó que el hecho de estar regulares, o con el reconocimiento de sus títulos universitarios, no garantiza a la población venezolana un acceso a empleos adecuados (Herrera y Cabezas, 2019). Acorde con un estudio específico acerca del acceso a empleo formal por parte de extranjeros en una ciudad intermedia del Ecuador, al crecer el flujo migratorio, los migrantes ven limitado su acceso al trabajo por parte de ciertos empleadores que reaccionan en forma discriminatoria y xenófoba, puesto que prefieren contratar personal local (Malo, 2018).

Si bien todavía se conoce poco sobre la inserción laboral de los migrantes en los diferentes países estudiados, se aprecian ciertas coincidencias. Se trata de una población joven, un gran porcentaje se concentra en edades productivas y reproductivas. La inserción laboral es inmediata porque tiene la necesidad de sobrevivir y de enviar dinero a los familiares que se quedaron en Venezuela. En cuanto a las actividades que realiza, coincide nuevamente en los tres países que se inserta en empleos no cualificados, en el mercado informal o de manera informal en empleos formales, pero sin contratos ni acceso a prestaciones legales, con altas probabilidades de ser abusada y explotada, con bajos salarios y muchas veces $\sin$ recibir pago.

Estas situaciones de precariedad se agudizaron drásticamente con el confinamiento y con excepción de aquellos migrantes más asentados, con empleos formales o con emprendimientos más consolidados, la gran mayoría no encontró los medios para vivir el día a día durante la pandemia y tampoco pudo acceder a los pocos programas de protección social impulsados por los gobiernos. La actual situación de crisis, asimismo, parece haber agudizado reacciones xenófobas de parte de la población local que ya estaban particularmente presentes en los tres países. Diversos trabajos han mostrado que uno de los factores que empeora la integración social y la inserción laboral es la discriminación que ha sentido la población migrante venezolana en sus lugares de trabajo y en sus viviendas (Freier y Castillo, 2020). Durante la pandemia se documentaron evicciones en Perú y Ecuador. No es de sorprender entonces que los venezolanos hayan emprendido el camino de regreso hacia sus hogares. 


\section{Conclusiones}

El éxodo venezolano es el fenómeno migratorio más relevante de los últimos 50 años en América del Sur por su magnitud, rapidez y sus características únicas que hemos tratado de trazar en este texto. Se trata de la migración desde un país sin tradición emigrante, pero con una historia de inmigración importante, no sólo desde Europa sino desde los mismos países andinos que ahora se han convertido en receptores. Más allá de esta reversión histórica, existen redes intergeneracionales en las tres naciones de acogida que han facilitado en algunos casos la llegada, la inserción laboral, la consecución de papeles de residencia y también el movimiento entre ciudades y entre países de la misma población. Ahora bien, la existencia de esas redes que permiten la movilidad se asienta en una dimensión estructural y en otra de carácter político que las moldean: la precariedad laboral y el endurecimiento de las medidas de control migratorio. Ambos procesos son a su vez resultado de las crisis que experimentan los países de acogida que se expresan en deterioro del mercado laboral y creciente xenofobia. Al contrario de las narrativas clásicas de movilidad social ascendente de las poblaciones migrantes, a medida que transcurre el tiempo en sus nuevos lugares de asentamiento, la población venezolana vive un proceso descendente en los últimos años que con la llegada de la pandemia se ha desmoronado. En ese contexto, el regreso a casa antes que el quédate en casa se construye como una prioridad para muchas familias venezolanas que han emprendido el retorno en medio de las más drásticas medidas de inmovilidad y cierre de fronteras que se han conocido en la región.

\section{Referencias}

Acosta Arcarazo, Diego y Luisa Feline Freier (2015), "Discursos y políticas de inmigración en Sudamérica. ìHacia un nuevo paradigma o la confirmación de una retórica sin contenido?», Remhu: Revista Interdisciplinar da Mobilidade Humana, 23(44), pp. 171-189, en https://dx.doi.org/10.1590/1980-85852503880004411

Alto Comisionado de las Naciones Unidas para los Refugiados (ACNUR) (2019), «Situación en Venezuela», en https://www.acnur.org/situacion-en-venezuela.html Álvarez de Flores, Raquel (2007), «Evolución histórica de las migraciones venezolanas. Breve recuento", Aldea Mundo, 11(22), pp. 89-93. 
Acosta Arcarazo, Diego y Luisa Feline Freier (2018), «Regional migration management in South America», en Anna Triandafyllidou (ed.), Handbook of Migration and Globalisation, Cheltenham, UK, Edward Elgar Publishing, pp. 659-696.

Acosta, Diego, Cécile Blouin y Luisa Feline Freier (2019), «La emigración venezolana: respuestas latinoamericanas», Documentos de trabajo. Fundación Carolina (3), en https://www.fundacioncarolina.es/wp-content/uploads/2019/04/DT_FC_03.pdf Bahar, Danny, Meagan Dooley y Cindy Huang (3 de diciembre de 2018), «Integración de los venezolanos en el mercado laboral colombiano», Brookings Institution, en https://www. brookings.edu/es/research/integracion-de-los-venezolanos-en-elmercado laboralcolombiano/

Banco Mundial (BM) (2019), Una oportunidad para todos. Los migrantes y refugiados venezolanos y el desarrollo del Perú, Washington DC.

(2020), Retos y oportunidades de la migración venezolana en Ecuador, Washington DC.

Berganza, Isabel, Cécile Blouin y Luisa Feline Freier (2018), «La aplicación de la definición de Cartagena a las personas venezolanas en el Perú», Documento de Trabajo CIUO DD1805, Perú, Universidad del Pacífico.

Bermúdez, Ángel (29 de julio de 2019), «Cómo impacta la crisis migratoria venezolana en la economía de otros países de América Latina", BBC News, en https://www. bbc.com/mundo/noticias-america-latina-49119834

Blouin, Cécile y Luisa Feline Freire (2019), "Población venezolana en Lima: entre la regularización y la precariedad», en Luciana Gandini, Fernando Lozano Ascencio y Victoria Prieto (coords.), Crisis y migración de población venezolana. Entre la desprotección y seguridad jurídica en ciudades latinoamericanas, Ciudad de México, Universidad Nacional Autónoma de México, pp. 157-184.

Cabrera Serrano, Donna, Gabriela M. Cano Salazary Alexandra Castro Franco (2019), «Procesos recientes de movilidad humana entre Venezuela y Colombia 20162018», en Luciana Gandini, Fernando Lozano Ascencio y Victoria Prieto (coords.), Crisis y migración de población venezolana. Entre la desprotección y seguridad jurídica en ciudades latinoamericanas, Ciudad de México, Universidad Nacional Autónoma de México, pp. 59-94.

Cañizales, Andrés (7 de agosto de 2018), «Antes de la diáspora. La Venezuela que acogía a inmigrantes», Prodavinci, en https://prodavinci.com/antes-de-la-diaspora-la-venezuela -que-acogia-inmigrantes/

Castro Franco, Alexandra (2019), «El acceso a la nacionalidad colombiana: nuevas realidades, nuevos retos», en Alexandra Castro Franco (ed.), Venezuela migra: aspectos sensibles del éxodo hacia Colombia, Bogotá, Universidad Externado de Colombia. 
Célleri, Daniela (2019), Situación laboral y aporte económico de inmigrantes en el norte de Quito-Ecuador. Una primera aproximación cuantitativa para dialogar sobre política pública, Quito, Friedrich-Ebert-Stiftung (FES)/ Instituto Latinoamericano de Investigaciones Sociales (Ildis).

Delgado de Smith, Yamile y Mónica R. Abellana Chaybub (2009), «Venezuela y migración. El trabajo como agente de cambio", Anuario del Instituto de Derecho Comparado (32), pp. 229-243.

Estado Peruano (2019), «Superintendencia Nacional de Migraciones», en https://www. gob.pe/migraciones

Freier, Luisa Feline y Soledad Castillo Jara (2020), «El desplazamiento venezolano y las políticas de Colombia, Ecuador y Perú», Revista La Brújula (114), en https://www. revistabrujula.org/el-desplazamiento-venezolano-y-las-

Freitez Landaeta, Anitza (2018), «La emigración venezolana en tiempos de crisis», en Anitza Freitez Landaeta (coord.), Espejo de la crisis humanitaria venezolana. Encuesta Nacional de Condiciones de Vida 2017, Caracas, Abediciones, pp. 219-239. (2019), "Crisis humanitaria y migración forzada desde Venezuela», en Luciana Gandini, Fernando Lozano Ascencio y Victoria Prieto (coords.), Crisis y migración de población venezolana. Entre la desprotección y seguridad jurídica en ciudades latinoamericanas, Ciudad de México, Universidad Nacional Autónoma de México, pp. 33-58.

Gandini, Luciana, Fernando Lozano Ascencio y Victoria Prieto (2019), «El éxodo venezolano: migración en contextos de crisis y respuestas de los países latinoamericanos», en Luciana Gandini, Fernando Lozano Ascencio y Victoria Prieto (coords.), Crisis y migración de población venezolana. Entre la desprotección y seguridad jurídica en ciudades latinoamericanas, Ciudad de México, Universidad Nacional Autónoma de México.

Herrera, Gioconda (2019), «From immigration to transit migration? Race and gender entanglements in new migration to Ecuador», en Xóchitl Bada, Andreas Feldmann y Stephanie Schütze (eds.), New migration patterns in the Americas. Challenges for the 21st Century, Palgrave, Migration and Citizenship Series.

(coord.) (2020), Voces y experiencias de la niñez y adolescencia venezolana migrante en Brasil, Colombia, Ecuador y Perú, Buenos Aires, Consejo Latinoamericano de Ciencias Sociales, en https://www.clacso.org/informe-voces-y-experiencias -de-la-ninez-y-adolescencia-venezolana-migrante-en-brasil-colombia-ecuador-y-peru Herrera, Gioconda y Gabriela Cabezas Gálvez (2019), «Ecuador: de la recepción a la disuasión. Políticas frente a la población venezolana y experiencia migratoria 
2015-2018», en Luciana Gandini, Fernando Lozano Ascencio y Victoria Prieto (coords.), Crisis y migración de población venezolana. Entre la desprotección y seguridad jurídica en ciudades latinoamericanas, Ciudad de México, Universidad Nacional Autónoma de México, pp. 125-156.

Instituto Nacional de Estadística e Informática Perú (INEI) (2018), «Características sociodemográficas de la población venezolana censada en el año 2017», en https://www.inei. gob.pe/media/MenuRecursivo/publicaciones_digitales/Est/Lib1577/Libro02.pdf (2019), Condiciones de vida de la población venezolana que reside en Perú. Resultados de la "Encuesta dirigida a la población venezolana que reside en el país". Enpove 2018, en https://www.inei.gob.pe/media/MenuRecursivo/publicaciones digitales/Est/Lib1666/libro.pdf

Malo, María Gabriela (2018), «Access to formal employment and mobility: Colombian and Venezuelan forced migrants in Ecuador» (Tesis de maestría), University of London, School of Advanced Study.

Marulanda, Claudia, Heidy Cubillos, Juan Pablo Ulloa y Liana Castañeda (2018), «Inclusión laboral de la población migrante venezolana laboralmente activa en Bogotá» (Tesis de especialidad), Universidad Piloto de Colombia, Bogotá D.C.

Migración Colombia (2019), "Total de venezolanos en Colombia» (corte a 31 de marzo de 2019), en http://www.migracioncolombia.gov.co/venezuela/RADIOGRAFIA\%20 VENEZOLANOS\%20EN\%20COLOMBIA\%20MARZO\%202019_1.pdf

Organismo de las Naciones Unidas para la Migración (OIM-DTM) (2018), «Monitoreo de flujo de población venezolana: Colombia», en https://migration.iom.int/ system/tdf/reports/Colombia2018.PDF 2 file $=1 \&$ type $=$ node\&id $=5499$ (4 de marzo de 2019), "Monitoreo de flujo de población venezolana: Ecuador», en http://www.oim.org.ec/2016/iomtemplate2/news/monitoreo-deflujo-de-población -venezolana-ecuador-ronda4-marzo-2019

Paéz, Daniel Santiago (2019), «La inmigración venezolana impacta al mercado laboral en Colombia», El Libre Pensador. Universidad Externado de Colombia 24, en https:// librepensador.uexternado.edu.co/la-inmigracion-venezolana-impacta-al-mercado laboral-en-colombia/

Plataforma de Coordinación para Refugiados y Migrantes de Venezuela (R4V) (2019), «RMRP 2020 Dashboard», en https://r4v.info/es/situations/platform?/\%C5\%B7\%C 3\%C0\%BC\%CB\%C5\%AE/

(2020), «Refugiados y migrantes de Venezuela», en https://r4v.info/es/ situations/platform/location/7512 
Secretaría Nacional de Educación Superior, Ciencia, Tecnología e Innovación (Senescyt) (2019), Base excel sobre reconocimientos de títulos universitarios a extranjeros de origen venezolana, Quito, Senescyt.

Selee, Andrew, Jessica Bolter, Betilde Muñoz-Pogossian y Miryam Hazán (30 de enero de 2019), "Creatividad dentro de la crisis: opciones legales para inmigrantes venezolanos en América Latina» (Podcast), Migration Policy Institute, en https://www. migrationpolicy.org/events/creatividad-dentro-de-la-crisis-opciones-legales-para -inmigrantes-venezolanos-en-america.

Torrado, Santiago (26 de noviembre de 2019), «Venezuela superaría en 2020 el fenómeno migratorio sirio», El País, en https://elpais.com/internacional/2019/11/19/actualidad/1574128387 157435.html

Universidad Católica Andrés Bello (UCAB) (2018), «Encuesta Nacional de Condiciones de Vida (Encovi) (2014-2018)», en https://encovi.ucab.edu.ve/ 